\title{
Amniotic Membrane Transplantation as an Alternative in Chemical Injury to Cornea
}

\author{
Dr. Ashok Rathi ${ }^{1 *}$, Dr. R.S. Chauhan ${ }^{2}$, Dr. Nidhi Singh ${ }^{3}$, Dr. Gautam Jain ${ }^{4}$ \\ ${ }^{1,2}$ Professor, Regional Institute of Ophthalmology, Pt.B.D.Sharma, Post Graduate Institute of Medical Sciences, Rohtak (Haryana) India \\ ${ }^{3,4}$ Resident, Pt.B.D. Sharma, Post Graduate Institute of Medical Sciences, Rohtak (Haryana) India
}

\author{
DOI: $10.36348 /$ sjmps.2019.v05i11.012 \\ | Received: 12.11.2019 | Accepted: 19.11.2019 | Published: 28.11.2019 \\ *Corresponding author: Dr. Ashok Rathi
}

\section{Abstract}

A chemical injury of the eye presents a genuine, acute emergency and requires immediate evaluation and management. Ocular chemical injury management remains one of the most difficult ocular emergencies. The prognosis for an eye injury depends not only on the severity of the injury but also on the rapidity and mode of initial treatment. Reconstruction of ocular surface following chemical burn by amniotic membrane (AM) for grafting is a very effective technique. AM graft promotes epithelial regeneration and facilitates migration of epithelial cells. Eight years old boy presented with ocular chemical injury by chemical mixed water holi balloon in his left eye. Patient presented with severe pain, excessive watering, with swollen lids and conjunctiva. More than $90 \%$ of the cornea surface, whole of the bulbar as well as palpaberal conjunctiva was eroded and whole eye was stained with green colour (chemical). Amniotic Membrane Transplantation (AMT) done under general anesthesia with corneal continuous girdle suture, conjunctival forniceal lid sutures and finally Bandage Contact Lens was applied. Patient had three months follow regular follow up and was clinically asymptomatic.

Keywords: Chemical injury, ocular emergencies, Amniotic Membrane, Holi balloon, amniotic membrane transplantation, bandage contact lens.

Copyright @ 2019: This is an open-access article distributed under the terms of the Creative Commons Attribution license which permits unrestricted use, distribution, and reproduction in any medium for non-commercial use (NonCommercial, or CC-BY-NC) provided the original author and source are credited.

\section{INTRODUCTION}

Chemical injury of the eye produces an extensive damage to the ocular surface epithelium, cornea, conjunctiva, anterior segment and limbal stem cells resulting ion impairment to complete visual loss, Although the most devastating sequelae of chemical injuries-corneal melt, limbal stem cell deficiency and secondary glaucoma-tend to occur over the long term, effective diagnosis and treatment in the minutes and days following the initial injury often dictate the clinical course and can prevent tragic consequences[1]. It may result in visual impairment to total destruction of the eye. Clinically, transplantation of amniotic membrane (AM) as a permanent surgical graft has been shown to promote epithelialization and reduce inflammation, scarring and neovascularization [2,3]. Since only incomplete HLA antigens are found in amniotic membrane, it is immunologically inert and not rejected by the recipient [4].

\section{A CASE REPORT}

Holi is an Indian festival of colors, celebrated by applying various vibrant holi colours powdered or water-based, usually on the face. However, these colors take a heavy toll on health as they are made up of synthetic dyes which have harmful effects on the skin and mucocutaneous areas like the conjunctiva and ocular surface as well. This article is the case report of injury to eye of a child with water based holi colour and its treatment with amniotic membrane transplantation.

\section{CASE REPORT}

An 8 years old boy presented with history of injury to his left eye by a water based Holi colour balloon five hours before he presented to hospital. He complained of severe ocular irritation, pain, watering, photophobia and a decrease in visual acuity to $6 / 60$ in left eye. He was having severe lid oedema, palpaberal and bulbar conjunctival congested, chemosed and found necrosis \& $1 / 3^{\text {rd }}$ limbal ischemia. There was an epithelial defect in middle $2 / 3^{\text {rd }}$ of the corneal surface and stained with fluorescein. The whole eye was stained with greenish watery colour. 


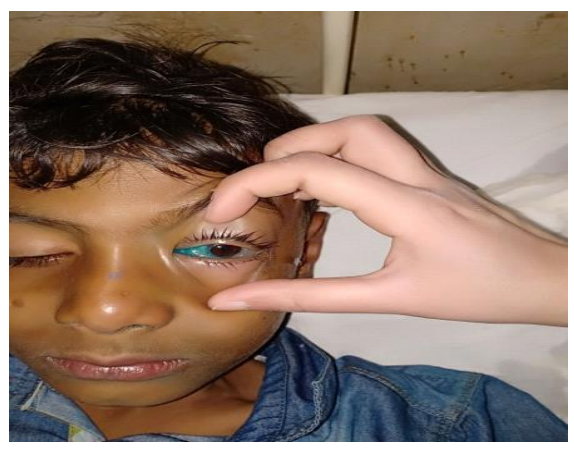

Fig-1: Left Eye-Before irrigation

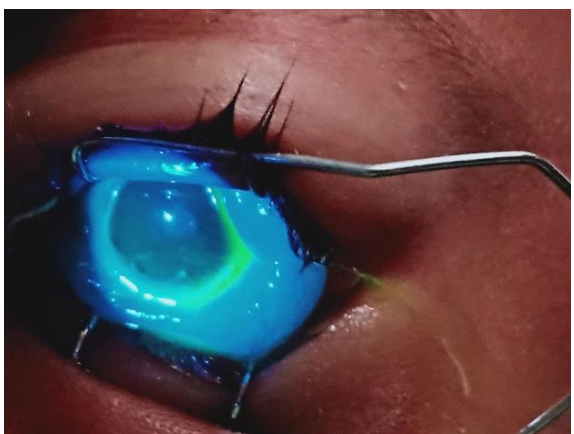

Fig-2: Fluoroscein staining after irrigation

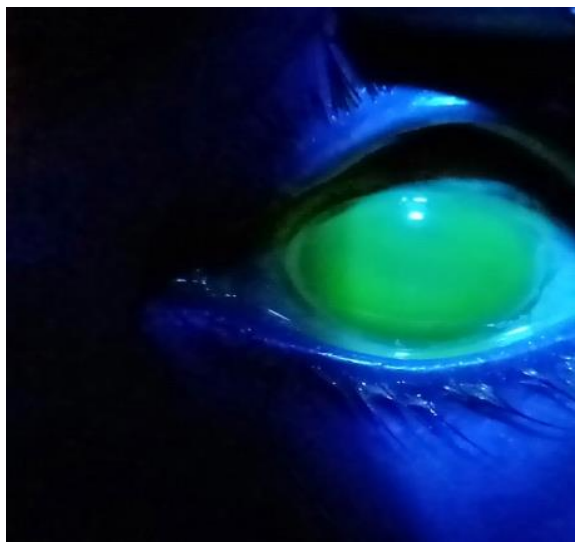

Fig-3: Complete epithelial damage

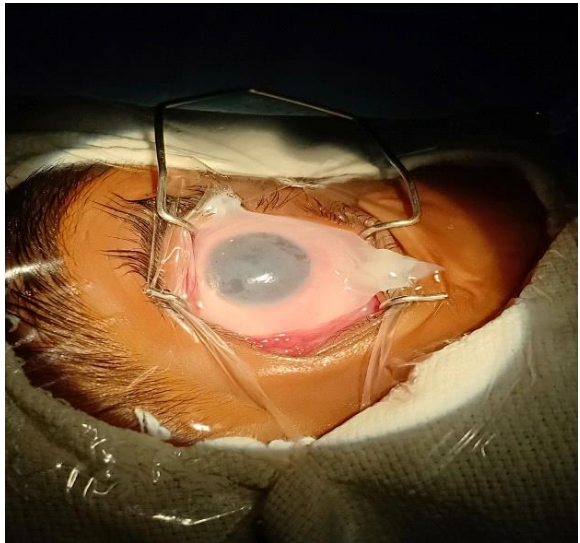

Fig-4: Amniotic Membrane grafting after one week of injury

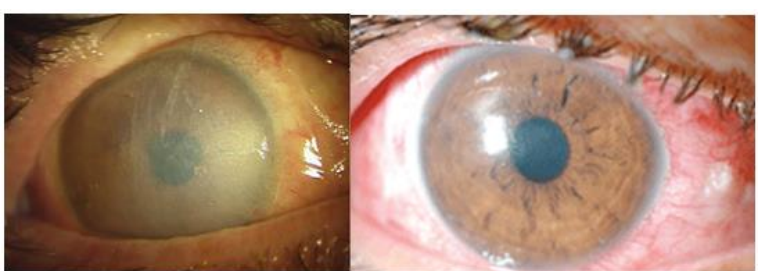

Fig-5: Clinical follow up after Amniotic Membrane grafting

Patient was admitted and examined under biomicroscopic slit lamp for extent of injury. Immediate intensive irrigation of his left eye with fresh normal saline was carried out. Extensively removal of the entire chemical mixed in balloon water from both the ocular surface especially from fornices by double eversion of eyelids. Whole of the necrosed conjunctiva was excised out under general anesthesia and then freshly prepared Amniotic Membrane transplantation with corneal girdle sutures was carried out. Prophylactic extended bandage contact lens applied overlying amniotic membrane. First postoperative follow up of AMT there was drastic reduction in the severe ocular irritation and pain with moxifloxacin-dexamethasone eye drops 6 times per day, $1 \%$ atropine eye drop \& carboxymethyl cellulose both 3 times a day. Patient discharged on $5^{\text {th }}$ day from the hospital in comfortable conditions with further follow up after one, 4 weeks and 3 months. On $3^{\text {rd }}$ month's regular follow up, patient was symptomatically relieved in pain watering and photophobia with minimum limbal ischemia \& cicatrisation. Cornea was clear with visual acuity of $6 / 9$ with painless full ocular movements in directions.

\section{DISCUSSION}

Traditionally Holi colours were prepared from natural sources but in recent times these colours are contaminated by hazardous substances like malachite green, rhodamine, gentian violet, auramine $\mathrm{O}$, proven by high performance liquid chromatography $[5,6]$. Other chemical adulterants in Holi colours include lead oxide, mercury sulphite, copper sulphate, chromium iodide, mica dust, silica, etc. to impart vibrant colours. Also, fungal contaminants have been documented in some Holi colours[7].

Hence, Holi colours known to have adverse effects and are responsible for cutaneous and ocular irritations. When injury to eye occurs with such chemicals, their endotoxins and fungal contaminants induce inflammatory response by induction of oxidative bursts in granulocytes [7]. These chemicals enter the eye and cause damage causing ocular discomfort, visual impairment and might result in complications which are vision threaten. The spectrum of manifestations of such injuries with Holi colour is those of alkaline chemical injury which may vary from a mild chemical conjunctivitis to an infected corneal ulcer $[8,9]$. But fewer studies have been done on specific clinical features in ocular injury with the chemicals of holi colours. Also, the epitheliopathy in such cases might be 
due to direct toxic effect of the chemicals and local inflammatory responses. Ocular injuries during holi primarily involve the young population [9].

Amniotic membrane, the outermost part of the foetal membrane, possess anti-inflammatory [10] anti scarring, stem cell proliferating and epithelization promoting effect on the ocular surface. It has been found useful in the treatment of ocular chemical burns [11].

The management of chemical injuries in the young boy was the challenge to restore the visual impairment at the earliest. The prognosis for an injured eye depends not only on the nature \& severity of injury but also on the rapidity and mode of treatment. The goal of treatment is restoration of the normal ocular surface anatomy and lid position, control of glaucoma and restoration of corneal clarity.

\section{CONCLUSION}

Conventionally, the acute stage is managed by promoting epithelialization and reducing inflammation to prevent progressive tissue melting in the acute phase and cicatricial complications in the chronic phase. AMT would promote healing of ocular surface by preventing leucocytic infiltrate, decreasing the duration and severity of inflammation and promoting the proliferating epithelial stem cells. It also provides drastic symptomatic relief as high lightened in this case too.

\section{REFERENCES}

1. Colby, K. A., \& Koo, E. B. (2011). Expanding indications for the Boston keratoprosthesis. Current opinion in ophthalmology, 22(4), 267-273.

2. Tseng, S. C., Espana, E. M., Kawakita, T., Di Pascuale, M. A., Li, W., He, H., ... \& Liu, C. Y. (2004). How does amniotic membrane work? The ocular surface, 2(3), 177-187.
3. John, T. (2004). Amniotic membrane transplantation in the management of severe ocular surface disease: indications and outcomes. The ocular surface, 2(3), 201-211.

4. Madhavan, H. N., Priya, K., Malathi, J., \& Joseph, P. R. (2002). Preparation of amniotic membrane for ocular surface reconstruction. Indian journal of ophthalmology, 50(3), 227.

5. GHOSE, S. Ocular Chemical Injuries: Chemical Characterizations and Clinical Profile Correlations.

6. Velpandian, T., Saha, K., Ravi, A. K., Kumari, S. S., Biswas, N. R., \& Ghose, S. (2007). Ocular hazards of the colors used during the festival-ofcolors (Holi) in India-Malachite green toxicity. Journal of hazardous materials, 139(2), 204-208.

7. Bossmann, K., Bach, S., Höflich, C., Valtanen, K., Heinze, R., Neumann, A., ... \& Süring, K. (2016). Holi colours contain PM10 and can induce proinflammatory responses. Journal of Occupational Medicine and Toxicology, 11(1), 42.

8. Dada, T., Sharma, N., \& Kumar, A. (1997). Chemical injury due to colours used at the festival of Holi. The National medical journal of India, 10(5), 256.

9. Ghosh, S. K., Bandyopadhyay, D., Chatterjee, G., \& Saha, D. (2009). The 'holi'dermatoses: Annual spate of skin diseases following the spring festival in India. Indian journal of dermatology, 54(3), 240.

10. Choi, Y. S., Kim, J. Y., Wee, W. R., \& Lee, J. H. (1998). Effect of the application of human amniotic membrane on rabbit corneal wound healing after excimer laser photorefractive keratectomy. Cornea, 17(4), 389-395.

11. Tsubota, K., Satake, Y., Ohyama, M., Toda, I., Takano, Y., Ono, M., \& Shimazaki, J. (1996). Surgical reconstruction of the ocular surface in advanced ocular cicatricial pemphigoid and Stevens-Johnson syndrome. American journal of ophthalmology, 122(1), 38-52. 